\title{
Congenital heart disease and prenatal exposure to exogenous sex hormones
}

\author{
DWIGHT T JANERICH, J MARIN DUGAN, SUSAN J STANDFAST, LINDA STRITE
}

British Medical fournal, 1977, 1, 1058-1060

\section{Summary}

One-hundred and four infants with congenital heart disease were identified from their birth certificates and matched with normal controls. Their gestational histories were examined to see whether they had been exposed to exogenous sex hormones. Exposure was 8.5 times more common among the infants with malformations than among controls. A history of hormone exposure was more common among those patients with multiple malformations, and the exposed infants were also more likely to have died (and to have died earlier) than those who had not been exposed, which suggests that hormone exposure causes severe types of malformations. The commonest type of exposure was to hormone pregnancy tests, which was needless exposure. Only two of the mothers of malformed infants had inadvertently used oral contraceptives in the first trimester.

\section{Introduction}

In 1973 Levy et al ${ }^{1}$ reported that transposition of the great vessels was significantly associated with the maternal use of oestrogen-progestogen preparations during pregnancy. Almost simultaneously, Nora and Nora ${ }^{2}$ presented similar data showing that the VACTEL syndrome of malformations (vertebral, anal, cardiac, tracheal, oesophageal, and limb) was also associated with maternal use of oestrogen-progestogen preparations during pregnancy. Subsequently three other reports $^{3-5}$ showed that the use of these preparations during pregnancy is associated with other types of birth defects. Nora and Nora, ${ }^{6}$ presenting further details, noted the importance of multiple malformations and the particular vulnerability of the cardiovascular system in the association with sex hormones. About $20^{\circ}{ }_{0}$ of infants with congenital heart disease also have developmental abnormalities of other systems. " We have conducted a series of retrospective matched case-control studies on several types of birth defects. The data reported here are from a controlled study designed to determine whether exogenous sex hormones during pregnancy are associated with CHD, either by itself or in combination with other types of malformations.

\section{Methods}

Infants were selected for study on the basis of the nominal description of the malformation recorded on the child's birth certificate. Only live born infants whose condition was serious enough to be recognised at birth were included. Our selection procedure excluded stillbirths but included malformed infants born alive who died soon afterwards. The infants studied were all born during 1971-4. Any

\footnotetext{
Department of Genetic Oncology, Division of Epidemiology, New York State Department of Health, Albany NY 12237

DWIGHT T JANERICH, DDS, MPH, director

J MARIN DUGAN, BA, research assistant

SUSAN J STANDFAST, MD, MPH, research physician

LINDA STRITE, MS, public health investigato
}

birth certificate mentioning CHD was eligible for study irrespective of whether the child had single or multiple defects.

Contacting and interviewing procedures were identical for patients and controls, and these procedures were the same as those used in our other studies. ${ }^{3 \times}$ Once we had located the mother of one of the infants with CHD we contacted the doctor who had signed the birth certificate for approval to interview the mother. Whenever approval was obtained we selected a control from the adjacent birth records, which are permanently bound in chronological order within the county. Births from New York counties outside New York city were eligible, and our matching procedure controlled for date of birth ( \pm 2 months) and county of residence. Each control was matched to its patient by mother's age ( \pm 2 years) and race. (Our final study group was $98 \%$ White.) The doctor who had signed the birth certificate of the control infant was then contacted, and from that point the cases and controls were handled identically. In each case we conducted a blind telephone interview with the mother. The interviewer was not aware of the mother's status until the end of the interview. We studied 104 infants who, according to their birth certificates, had CHD and their controls.

Through contacting doctors and mothers, we gained additional diagnostic information in some cases. We also searched for the death certificate of each infant with CHD and obtained the cause of death in those who had died. Although these infants had been included in the study solely on the basis of information recorded on the birth certificate, we eventually used the additional information to classify cases according to type of malformation. This classification was performed by one of us without knowledge of the data on drug use. Patients were subdivided in a generally stepwise fashion. Patients with definite CHD were subdivided from those with probable CHD but for whom we had insufficient information to identify specific defects. We also determined that five infants whom we had included definitely did not have CHD. Although these five infants did have other types of congenital malformations, CHD was ruled out by the additional diagnostic information.

The results of this subclassification are shown in table 1 . Seventy of the 104 infants had definite CHD (group 1), and 44 of these had died $(63 \%)$. Twenty-nine had probable CHD (group 2), and nine of these had died $(31 \%)$. The remaining five, none of whom had died, did not have $\mathrm{CHD}$ (group 3). Class 1 infants were subdivided according to the presence or absence of multiple malformations within the cardiovascular system, and groups 1 and 2 were further subclassified according to the presence of additional malformations outside the cardiovascular system.

\section{Results}

We compared the infants with CHD and controls in respect to maternal age, maternal education level, previous stillbirths, previous miscarriages, and previous live births. No noteworthy differences

TABLE I-Classification of cases of CHD according to specific defect and systems affected

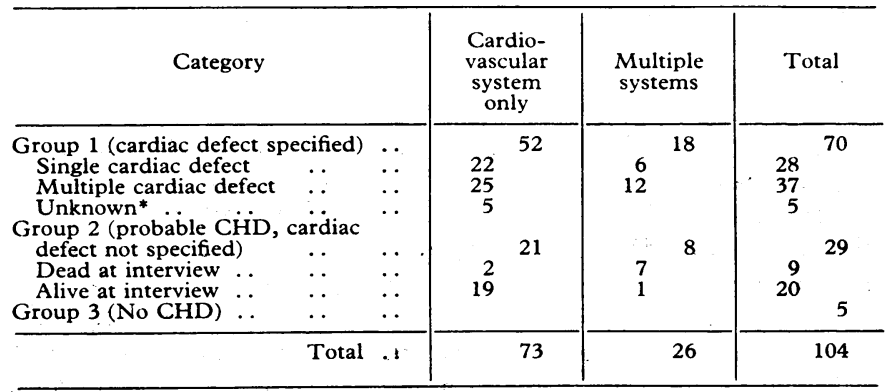

* Single cardiac defect was definitely present and there may have been others. 
were observed except in the category of previous live births. The mothers of the 104 infants with malformations had had a total of 151 previous live births, while the mothers of the controls had had only 125 previous live births. Since the patients and controls were successfully matched by maternal age, we saw no obvious explanation for this moderate increase in the number of previous live births among the cases. An increase in previous miscarriages or stillbirths among the mothers of the infants with malformations might have influenced the likelihood that supportive hormones would have been prescribed during the index pregnancy, but that was not the case since the observed parity increase was limited to live births.

Our primary concern was to discover whether the use of any type of sex hormone during pregnancy increased the risk of CHD in the offspring. We used the paired study design for analysing data. Hormone pregnancy tests, supportive hormone treatment, and inadvertent oral contraceptive use were grouped as hormone exposures. Among the mothers of the infants with malformations there were 18 exposures: 10 had had hormone pregnancy tests; six supportive hormone treatment; and two inadvertent oral contraceptive use. Among the mothers of controls there were three exposures: two had had hormone pregnancy tests and one supportive hormone treatment. Seventeen of the 18 exposures among the mothers of malformed infants were started in the first trimester, and all three hormone exposures among the control mothers were started during the first trimester

Table II shows the results of paired comparisons of hormone exposure among the entire group of 104 study pairs and among specified subgroups. The McNemar test was used to test for significance, and paired observations were used to calculate relative risks of exposure. The greater incidence of exposure among the patients was highly significant in the total group $(P<0.001)$ and the relative risk of hormone exposure was 8.5 . The same analysis, limited to the 70 patients in group 1 , showed that hormone exposure remained significant among the patients $(P<0.01)$, and the relative risk was 6.5 . $\mathrm{CHD}$ tends to be familial, and we analysed the exposure rate after removing the six infants who had a sibling with $\mathrm{CHD}$. The results remained significant $(\mathbf{P}<0.01)$. Finally we looked at exposure rates among the 51 patients who were still alive at the time of the interview (table II). Among this group the relative risk was only 3.0 and the association was not significant.

TABLE II-Hormone exposure among patient and control pairs in whole group and subgroups

\begin{tabular}{|c|c|c|c|c|c|c|}
\hline Group (No of pairs) & $\begin{array}{c}\text { Patients } \\
\text { exposed, } \\
\text { controls } \\
\text { un- } \\
\text { exposed }\end{array}$ & $\begin{array}{l}\text { Patients } \\
\text { un- } \\
\text { exposed, } \\
\text { controls } \\
\text { exposed }\end{array}$ & $\begin{array}{l}\text { Patients } \\
\text { and } \\
\text { controls } \\
\text { exposed }\end{array}$ & $\begin{array}{c}\text { Patients } \\
\text { and } \\
\text { controls } \\
\text { un- } \\
\text { exposed }\end{array}$ & $\begin{array}{c}\text { Relative } \\
\text { risk }\end{array}$ & $\begin{array}{c}\mathrm{P}^{*} \\
\text { value }\end{array}$ \\
\hline $\begin{array}{l}\text { Total study group (104) } \\
\text { Group } 1 \text { patients only } \\
\text { (70) } \\
\text { Familial cases removed } \\
\text { (98).. } \quad . \\
\begin{array}{c}\text { Patients surviving to } \\
\text { interview (51) }\end{array}\end{array}$ & $\begin{array}{r}17 \\
13 \\
15 \\
6\end{array}$ & $\begin{array}{l}2 \\
2 \\
2 \\
2\end{array}$ & $\begin{array}{l}1 \\
0 \\
1 \\
1\end{array}$ & $\begin{array}{l}84 \\
55 \\
80 \\
42\end{array}$ & $\begin{array}{l}8 \cdot 5 \\
6 \cdot 5 \\
7 \cdot 5 \\
3 \cdot 0\end{array}$ & $\begin{array}{l}<0.001 \\
<0.01 \\
<0.01 \\
\text { NS }\end{array}$ \\
\hline
\end{tabular}

*McNemar or paired $\chi^{2}$ test. NS $=$ Not significant.

We also examined the use of other types of treatment during pregnancy from the information provided by the mother. Altogether $91 \%$ of the mothers of infants with malformations $(95 / 104)$ and $80 \%$ of the mothers of controls $(83 / 104)$ used prescribed medication (including all treatment prescribed by a doctor that was used at any time during pregnancy). In the first trimester, eliminating those who used hormones and those who used only vitamins or iron, or both, 15 mothers of patients and 21 mothers of controls reported using some form of prescribed medication. We therefore found no evidence that the use of other medications during the first trimester weakened the strong association between CHD and hormones. We also examined the data on infections during pregnancy. No one had a history of exposure to rubella or any other known teratogenic infectious agents. In 10 patients and six controls there was a history of some type of infection during pregnancy, but this difference might easily have arisen by chance $(P \cdot 0 \cdot 3)$, and a history of infection did not influence the association between congenital heart disease and hormone use during pregnancy.

We examined the frequency of hormone exposure in relation to infant survival in group 1. Forty-four of these 70 infants had died.
For the entire group the association with hormone exposure was significant $(P<0.01)$ and the relative risk was 6.5 . In the 26 survivors the relative risk was only 3.0 , but among those who had died the relative risk was $10 \cdot 0$. The average age at death in those not exposed to hormones was 3.0 months; in the exposed group it was 1.3 months. Therefore hormone exposure was most strongly associated with the severe types of $\mathrm{CHD}$, which tend to cause early death.

We also examined the frequency of hormone exposure in relation to multiple malformations in group 1. Table III subdivides the 70 group 1 patients according to whether they had single or multiple malformations of the heart and coexistent malformations outside the cardiovascular system. In five cases there was insufficient evidence to classify the $\mathrm{CHD}$ as a single or multiple malformation. Exposures were more common among infants with coexistent malformations, irrespective of whether the malformation occurred inside or outside the cardiovascular system. Even when all five of the uncertain cases were assigned to either the single or multiple cardiac malformation category this pattern persisted. In the small group of 12 infants with multiple cardiac malformations plus malformations outside the cardiovascular system six were exposed to exogenous hormones during gestation.

TABLE III-Percentage of group 1 patients with a positive history of hormone exposure according to presence of single or multiple malformations

\begin{tabular}{|c|c|c|c|c|}
\hline Category & $\begin{array}{c}\text { Single } \\
\text { cardiac }\end{array}$ & $\begin{array}{l}\text { Multiple } \\
\text { cardiac }\end{array}$ & $\begin{array}{l}\text { Cardiac } \\
\text { status } \\
\text { uncertain }\end{array}$ & Total \\
\hline Cardiac defect only & $9 \cdot 1(2 / 22)$ & $16 \cdot 0(4 / 25)$ & $20 \cdot 0(1 / 5)$ & $13.5(7 / 52)$ \\
\hline affected systems & $0.0(0.6)$ & $50 \cdot 0(6 / 12)$ & $0.0(0 / 0)$ & $33 \cdot 3(6 / 18)$ \\
\hline Total & $7 \cdot 1(2 / 28)$ & $27 \cdot 0(10 / 37)$ & $20 \cdot 0(1 / 5)$ & $18 \cdot 6(13 / 70)$ \\
\hline
\end{tabular}

\section{Discussion}

Our results support the hypothesis that hormone exposure during pregnancy may cause CHD. Furthermore, our data strongly suggest that exogenous hormones during pregnancy are more strongly associated with multiple malformations than with single heart lesions. In future studies it will be important to determine whether this observation is also true for other types of combinations of multiple malformations. The actual number of cases caused by these agents cannot be directly estimated from a paired case-control study. Birth certificates tend to identify only the more severe and relatively uncommon types of $\mathrm{CHD}$. By using the point estimate of relative risk (8.5) from our data, and assuming that the frequency of the type of CHD that we studied is no more than one live born case among 2000 births, we can predict that no more than 19 additional cases of $\mathrm{CHD}$ would be produced by a similar level of hormone use during pregnancy among a population of 100000 births. If hormone-related cases of CHD tend to be more severe, and so the infant dies early, the actual burden of hormone-caused CHD among surviving infants is probably small, although not negligible.

Several studies on CHD and sex hormones have produced negative findings. ${ }^{9-11}$ Mulvihill et al $^{9}$ used a precise retrospective study design to investigate a group of cases selected from a CHD treatment unit, and their results were clearly negative. If, however, hormone-related CHD tends to be severe and have poor prognosis, it would be difficult to detect a hormone association among children with CHD who are brought for treatment of their lesion. MacMahon et al ${ }^{12}$ have shown that the life expectancy among children with CHD is short: nearly a quarter die in the first day, and about a half are dead by 3 months of age. Therefore negative findings in controlled series collected from cardiac treatment units might not reflect the true relation between these hormones and CHD.

The interpretation of the results of retrospective studies should be tempered by recognising the limitations of the data. Maternal recall may be an important source of bias and we have made considerable efforts to develop a standardised procedure for obtaining a uniform quality of data on both 
patients and controls. We have used these same study procedures for matched case-control studies of other birth defects (anencephaly (66 pairs); spina bifida (135 pairs); Down's syndrome (103 pairs); hypospadias (99 pairs)). Neither in the total group of 403 pairs, nor in any of the subgroups, did we find a significant or substantial increase in the number of patients exposed to hormones. This suggests that our study procedures do not produce results that are biased toward detecting hormone exposures among patients. Our study is not large in terms of number of cases, so that the results should be interpreted cautiously because the confidence limits on the relative risks tend to be wide. Our point estimate on relative risk of exposure is 8.5 and it is statistically significant, but it would be prudent to await the results of other studies before finally judging the actual relative risk value. Finally, our results suggest that other studies that include a greater proportion of less severe cases of CHD should find lower relative risk estimates than we have found. But this difference should not affect the attributable risk estimates for severe CHD among live births.

Inadvertent exposure to oral contraceptives during pregnancy represented the smallest proportion of exposures in the group we studied ( 2 out of 18). Both of these infants were boys and both died within the first week of life. In judging the riskbenefit of each of the three types of hormone exposure the small risk associated with inadvertent exposure through oral contraceptives seems negligible in comparison with the large-scale benefits from effective contraception. Hormone pregnancy tests were the most common type of exposure (10 out of 18). These represent needless exposures and their continued use is not justified because other types of pregnancy tests are available.
The risk benefit of supportive hormone treatment cannot be evaluated from any existing data. If the weight of clinical judgement still favours a possible benefit from supportive hormone treatment during pregnancy then a controlled clinical trial should certainly be conducted to determine whether the benefit outweighs the risk.

We thank Dr Margaret Hoff and the staff of the Office of Biostatistics, New York State Department of Health, for their help in analysing the data. This research was supported by Contract NO 2 HD 52802, National Institute of Child Health and Human Development.

\section{References}

${ }^{1}$ Levy, E P, Cohen, A, and Frazer, F C, Lancet, 1973, 1, 611.

2 Nora, J J, and Nora, A H, Lancet, 1973, 1, 941.

3 Janerich, D T, Piper, J M, and Glebatis, D M, New England Fournal of Medicine, 1974, 291, 697.

${ }^{4}$ Harlap, S, Prywes, R, and Davies, A M, Lancet, 1975, 1, 682.

5 Greenberg, G, et al, British Medical fournal, 1975, 2, 191.

- Nora, A H, and Nora, J J, Archives of Environmental Health, 1975, 30, 17.

Lancet, 1975, 2, 692.

${ }^{8}$ Janerich, D T, Flink, E M, and Keogh, M, British fournal of Obstetrics and Gynaecology, 1976, 83, 617.

${ }^{9}$ Mulvihill, J J, Mulvihill, C G, and Neill, C A, Teratology, 1974, 9, A30.

10 Hook, E B, et al, Teratology, 1974, 9, A21.

1 Yasuda, M, and Miller, J R, Teratology, 1975, 12, 239.

12 MacMahon, B, McKeown, T, and Record, R G, British Heart Fournal, $1953,15,121$.

(Accepted 17 February 1977)

\title{
Nicotine chewing gum as a substitute for smoking
}

\author{
M A H RUSSELL, S R SUTTON, C FEYERABEND, P V COLE, Y SALOOJEE
}

British Medical fournal, 1977, 1, 1060-1063

\section{Summary}

The capacity of nicotine-containing chewing gum to produce plasma nicotine levels comparable to heavy cigarette smoking was tested in 21 subjects. On a fixed schedule of one piece of gum ( $4 \mathrm{mg}$ nicotine) per hour, the average peak plasma nicotine concentration was 175.7 $\mathrm{nmol} / \mathrm{l}(28.5 \mathrm{ng} / \mathrm{ml})$ compared to $189.3 \mathrm{nmol} / 1(30.7 \mathrm{ng} / \mathrm{ml})$ obtained from normal ad libitum smoking. Unpleasant side effects were common and in some cases plasma nicotine concentrations were two and even three times as high as with smoking. The chewing gum provided some satisfaction to all but four subjects, but its degree was not

Addiction Research Unit, Institute of Psychiatry, London SE5 8AF M A H RUSSELL, MRCP, MRCPSYCH, senior lecturer and honorary consultant psychiatrist

S R SUTTON, BA, MSC, research worker

Poisons Unit, New Cross Hospital, London SE14 5BH

C FEYERABEND, BSC, research worker

Anaesthetic Research Laboratory, St Bartholomew's Hospital, London EC1A 7BE

P V COLE, MB, FFARCS, consultant anaesthetist

Y SALOOJEE, MIBIOL, research worker related to the concentration of plasma nicotine it produced, neither was there an inverse relation between the plasma nicotine concentration while taking the gum and the subjective sense of missing cigarettes. This suggests that the capacity of the gum to act as a substitute for smoking is not necessarily related to its capacity to provide nicotine. Flexible dosage dictated by individual needs would probably lower the incidence of side effects and might secure closer approximation to smoking concentrations of plasma nicotine.

\section{Introduction}

The development of nicotine chewing gum as an aid to cigarette withdrawal ${ }^{1-5}$ is based on two assumptions. Firstly, that nicotine intake is an important component of dependence on smoking, and secondly that absorption of nicotine from chewing gum is sufficient to reproduce whatever positive pharmacological effects the smoker seeks to obtain, or to prevent whatever negative nicotine withdrawal effects he smokes to relieve or avoid. Neither assumption is yet unequivocally established, though much circumstantial evidence points to the importance of nicotine for most smokers. ${ }^{6}$

In assessing the potential clinical usefulness of nicotine chewing gum it would seem essential firstly to show that it can produce plasma nicotine concentrations comparable to those obtained from cigarette smoking. It has been available in two strengths, with $2 \mathrm{mg}$ or $4 \mathrm{mg}$ nicotine in each piece of gum. Owing to its local irritancy and lack of palatability we found that 